\title{
Spectroscopy and Mineralogy of a Fresh Meteorite Fall Kamargaon (L6) Chondrite
}

\author{
BHASKAR J SAIKIA ${ }^{1, *}$, G PARTHASARATHY ${ }^{2}$, R R BORAH ${ }^{3}$, M SATYANARAYANAN $^{2}$, \\ R BORTHAKUR ${ }^{3}$ and P CHETIA ${ }^{4}$ \\ ${ }^{1}$ Department of Physics, Anandaram Dhekial Phookan College, Nagaon 782 002, India \\ ${ }^{2}$ National Geophysical Research Institute (CSIR-NGRI), Hyderabad 500 007, India \\ ${ }^{3}$ Department of Physics, Nowgong College, Nagaon 782 001, India \\ ${ }^{4}$ Jorhat Science Centre and Planetarium, Jorhat 786 001, India
}

(Received on 01 May 2017; Revised on 10 June 2017; Accepted on 11 August 2017)

\begin{abstract}
We report spectroscopic, bulk, trace element and mineralogical composition of a fresh meteorite fall at Bali-Chapori village, near Kamargaon Town, Assam, India $\left(26^{\circ} 37^{\prime} 56^{\prime \prime} .99\right.$ N; $\left.93^{\circ} 46^{\prime} 11^{\prime \prime} .51 \mathrm{E}\right)$ on November $13^{\text {th }}, 2015$. The whole rock analyses and the composition of olivine and pyroxene indicate that the meteorite is an ordinary chondrite belonging to the group L6. The spectroscopic (Raman, FTIR, XRD) and petrographical (HR-ICP-MS, EPMA, XRF) studies reveal that the major constituents of the meteorite is olivine $\left[(\mathrm{Mg}, \mathrm{Fe})_{2} \mathrm{SiO}_{4}\right]$, pyroxene, and metal.
\end{abstract}

Keywords: Meteorite; Spectroscopy; Mineralogy; Kamargaon; Ordinary Chondrites

\section{Introduction}

Chondritic meteorites are the oldest and most primitive rocks in the solar system. Chondrites are stony meteorites that have not been modified due to melting or differentiation of the parent body. Chondrites are broadly ultramafic in composition, consisting largely of iron, magnesium, silicon and oxygen and account for $87 \%$ of all meteorites observed to fall. The largest group of chondritic meteorites is known as the ordinary chondrites, which account for $80 \%$ of all known meteorites (Philip et al., 2000). Ordinary chondrites are divided into three groups, viz. H-type which have high total Fe-contents, L-type having low total Fecontents, and LL-type having very low metallic Fe relative to the total $\mathrm{Fe}$, as well as low total $\mathrm{Fe}$-content. Chemical distinction among the H, L, LL-group chondrites depends on the distribution of iron between metal and silicates. It has been established that there is no or very little compositional overlap among these $\mathrm{H}, \mathrm{L}$, and LL chondrites. Changes in chemical composition (ferrous, metallic, and total iron contents and $\mathrm{Fe} / \mathrm{Ni}$ ratios in the metal) is used to characterize different chondrites (Hutchison, 2004).

In this paper we report spectroscopy, composition and mineralogy of a recent meteorite fall at Bali-Chapori village $\left(26^{\circ} 37^{\prime} 56.99 \mathrm{~N}\right.$; $93^{\circ} 46^{\prime}$ $11.51 \mathrm{E})$, near Kamargaon town in Golaghat District of Assam, India, on 13th November 2015 at 12:00 hrs (Local time). The stone was fully covered with fusion crust and had well rounded edges and well developed regmaglypts (thumbprint like impressions) on its surface, that are formed by ablation of material from the surface as a meteor passes through the Earth's atmosphere. The strike of the meteorite made an impact pit of about $40 \mathrm{~cm}$ diameter and penetrated the ground nearly a meter in depth. A single piece of meteorite of weight $12.095 \mathrm{~kg}$ was recovered and has been preserved under the custody of the local police station. The fusion crust (about $1 \mathrm{~mm}$ of thickness) and the regmaglypts are clearly visible on the surface of the meteorite (Fig. 1) (Saikia et al., 2017a). Five recorded falls in North-eastern region of India till date are: Assam L5 (1846), Goalpara Ureilite (1868), Sabrum LL6 (1999), Dergaon H5 


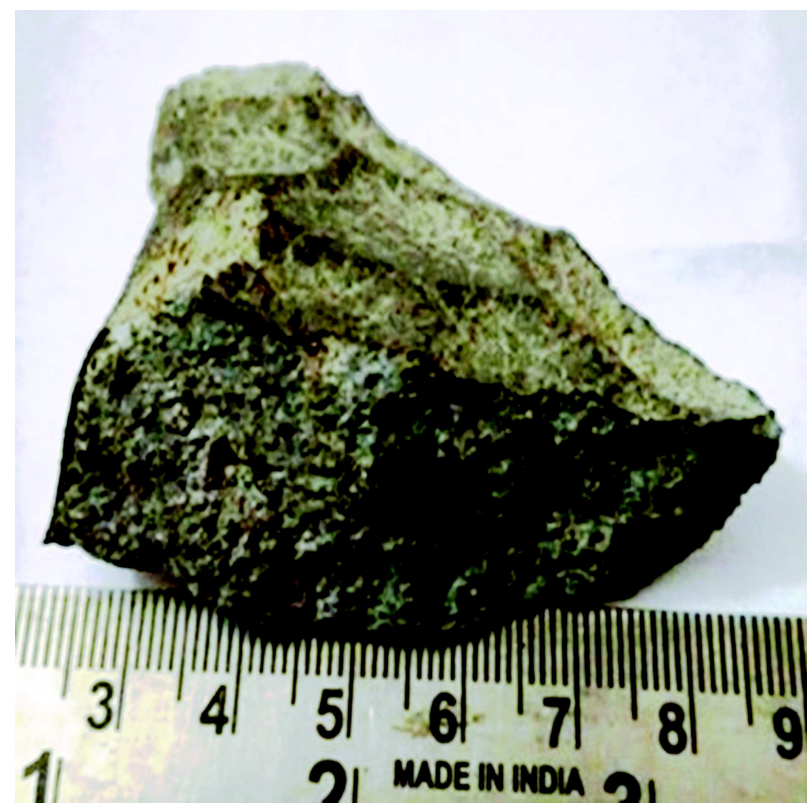

Fig. 1: A fraction of Kamargaon meteorite

(2001) and Mahadevpur H4/5 (2007) and have been documented by Grady, (2000), Ghosh et al. (2002); Saikia et al. (2007, 2008, 2009 a,b). Kamargaon is the most recent fall.

\section{Methods}

Raman spectra were collected on powdered bulk meteorite sample using a $\mathrm{Ar}^{+}$laser excitation source having wavelength $488 \mathrm{~nm}$ coupled with a Jobin-Yvon Horiba LabRam-HR Micro Raman spectrometer (equipped with an Olympus microscope with 50X objectives and a motorized $x-y$ stage and using 1800 grooves/mm grating). The spectral resolution was around $0.1 \mathrm{~cm}^{-1}$ in the range from 100 to $3000 \mathrm{~cm}^{-1}$ and the spectra were collected with counting times of 10 to $60 \mathrm{~s}$. In Raman spectra only wave numbers between $100 \mathrm{~cm}^{-1}$ and $1400 \mathrm{~cm}^{-1}$ are given due to the absence of any characteristic and significant bands between $1400 \mathrm{~cm}^{-1}$ and $3000 \mathrm{~cm}^{-1}$.

Powdered meteorite sample was analyzed for the whole rock chemical composition by X-ray fluorescence was estimated on powdered samples using (Bhandari et al., 2005, 2008, 2009). The precision and accuracy of the data is $\pm 2 \%$, and average values of three replicates were taken for each determination. X-ray diffraction analysis was also performed on powdered sample. X-ray diffractogram was measured using a Siemens D5000 diffractometer
$(40 \mathrm{kV}, 30 \mathrm{~mA})$ with $\mathrm{Cu} \mathrm{K} \alpha$ radiation $\left(\lambda_{\mathrm{K} \alpha 1}=1.5406\right.$ $\AA$, $\lambda_{\mathrm{K} \alpha 2}=1.54439 \AA$ ), $2 \theta$ range between $15^{\circ}$ and $65^{\circ}$, step size of $0.02^{\circ} 2 \theta, 1.2 \mathrm{~s} / \mathrm{step}$, divergence slit $=0.5$ $\mathrm{mm}$, and receiving slit $=0.3 \mathrm{~mm}$.

The infrared spectrum was acquired from the homogenized spectrophotometric grade $\mathrm{KBr}$ and powdered meteorite pellet (1:20) using Perkin-Elmer system 2000 FTIR spectrophotometer with heliumneon laser as the source reference and at a resolution of $4 \mathrm{~cm}^{-1}$. The experimental conditions were identical to those used in studies on Dergaon and Mahadevpur meteorites (Saikia et al., 2009 a, b).

Quantitative mineral analyses were carried out using a JEOL JXA 8900 electron microprobe (EMPA) operated at $15 \mathrm{keV}$ and a probe current of $15 \mathrm{nA}$. Natural and synthetic standards of well-known compositions were used as standards for wavelength dispersive spectrometry. The matrix corrections were made according to the $\phi \rho(z)$ procedure (Armstrong, 1991). Trace elements including rare earth (REE) and high field strength elements (HFSE) were determined by high resolution inductively coupled mass spectrometer (HR-ICP-MS) (Nu Instruments Attom $^{\circledR}, \mathrm{UK}$ ) in jump-wiggle mode at resolution of 300 which permits all the element of interest to be measured accurately. The sample introduction consisted of a standard Meinhard ${ }^{\circledR}$ nebulizer with a cyclonic spray chamber housed in Peltier cooling system. All quantitative measurements were performed using the instrument software (Attolab v.2.8), while the data processing was done using $\mathrm{Nu}$ Quant ${ }^{\circledR}$ (Release 2.0) which uses knowledge-driven routines in combination with numerical calculations (quantitative analysis) and performs an automated or manual interpretation of the spectrum of interest. The instrument was optimized using $1 \mathrm{ppb}$ tuning solution and the sensitivity for ${ }^{114}$ In was about 1 million cps. Oxide and oxy-hydroxide ratios were $<0.2 \%$ and the doubly charged ions ratio was $<3 \%$. Mass bias fractionation and several well-known isobaric interferences were addressed by using certified geochemical reference materials. Precision and accuracy were better than RSD 3\% for the majority of trace elements.

\section{Results and Discussion}

The petrographic investigations indicated the presence of olivine, orthopyroxene, feldspar, and opaque 
minerals taenite, iron metal (kamacite) and troilite (Fig. 2A,B,C). The EPMA data (Table 1) show evidence of opaque metallic phases with kamacite and sulfide phase trolite with less than $0.4 \mathrm{wt} \%$ of Ni (Fig. 2A). The olivine composition is estimated to Fo $=75.50$ $78.98 \mathrm{~mol} \% ; \mathrm{Fa}=20.80-25.0 \mathrm{~mol} \%$. Kamacite Co concentrations vary systematically in various chondrite chemical groups; kamacite in $\mathrm{H}, \mathrm{L}$, LL group chondrites contain $0.4-0.5,0.7-1.0$ and $1.5-3$ wt. \% Co, respectively (Rubin, 1990; Reisener and Goldstein, 2003). The kamacite Co content (0.811-0.827 wt. \%) in Kamargaon meteorite is similar to L group chondrites. Troilite contains $<0.4 \mathrm{wt} \% \mathrm{Ni}$, suggesting slow cooling (Smith and Goldstein, 1977). Metal and troilite occur both as separate grains and paired assemblages. Such a texture is similar to that of higher petrologic type ( $\sim 6)$ ordinary chondrites (van Schmus and Wood, 1967). The observed opaque taenite with Ni content of $22 \%$ confirms that Kamargaon meteorite is L6 type ordinary chondrite (Brearley and Jones, 1998). Secondary grains of feldspar with olivine are also observed. Presence of veins of feldspar and troilite exhibiting shock induced melt vein in the Kamargaon meteorite (Fig. 2B,C) is consistent with shock stage S4-S6 (Stoffler et al., 1991).

Table 1: Electron-Probe Micro Analysis data of Kamargaon meteorite

\begin{tabular}{lcccc}
\hline & $\begin{array}{c}\text { Olivine } \\
(\mathrm{N}=20)\end{array}$ & $\begin{array}{c}\text { Pyroxene } \\
(\mathrm{N}=12)\end{array}$ & $\begin{array}{c}\text { Feldspar } \\
(\mathrm{N}=10)\end{array}$ & $\begin{array}{c}\text { Kamacite } \\
(\mathrm{N}=10)\end{array}$ \\
\hline $\mathrm{SiO}_{2}$ & 38.20 & 54.78 & 66.00 & $\mathrm{Fe}=92.00$ \\
$\mathrm{Al}_{2} \mathrm{O}_{3}$ & - & 0.10 & 22.20 & $\mathrm{Co}=0.70$ \\
$\mathrm{FeO}$ & 22.40 & 14.12 & 0.10 & $\mathrm{Ni}=7.00$ \\
$\mathrm{MnO}$ & - & 0.12 & - & \\
$\mathrm{MgO}$ & 39.50 & 30.00 & - & \\
$\mathrm{CaO}$ & - & - & - & \\
$\mathrm{NiO}$ & - & 0.80 & 2.20 & \\
$\mathrm{Na}{ }_{2} \mathrm{O}$ & - & - & 8.60 & \\
$\mathrm{~K}_{2} \mathrm{O}$ & - & - & 1.20 & \\
$\mathrm{Total}$ & 100.10 & 99.82 & 100.3 & 99.7 \\
\hline
\end{tabular}

$\mathrm{N}$-indicates the total numbers of grains for the EPMA analyses

Major and trace element abundances of Kamargaon meteorite sample is analyzed by X-ray fluorescence spectrometry (XRF) and high resolution inductively coupled plasma mass spectrometry (HRICP-MS). The results facilitated determination of the major elemental composition of Kamargaon (Table
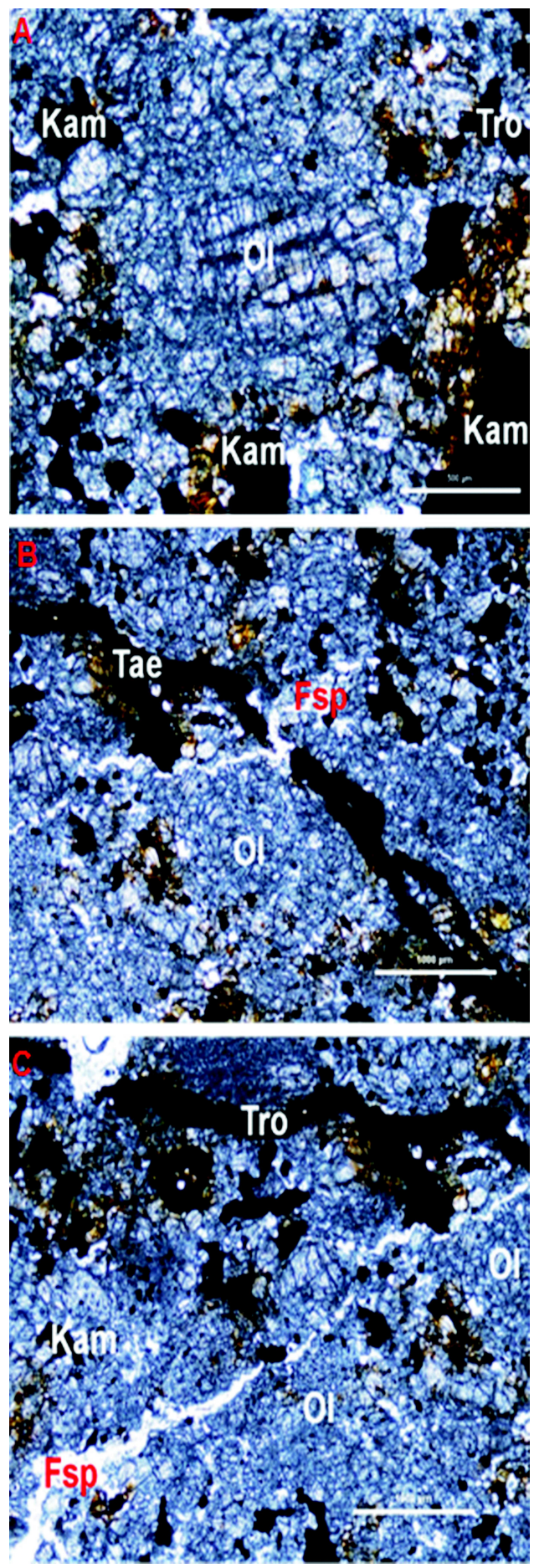

Fig. 2: (A) Thin section of Kamargaon meteorite. The olivine (Ol) composition (Fo $=78.98$ to $75.5 \mathrm{~mol} \% ; \mathrm{Fa}=\mathbf{2 0 . 8 0}$ to $25.5 \mathrm{~mol} \%$ and $\mathrm{Tp}=0.88 \mathrm{~mol} \%$ ) and opaque metallic phases with kamacite (Kam) and sulfide phase trolite (Tro) with Ni less than $0.4 \mathrm{wt} \%$, indicative of $\mathrm{L6}$ type chondrite, (B) Olivine, with feldspar (Fsp) secondary grains and opaque taenite (Tae) with $\mathrm{Ni}$ content of $22 \%$ confirm that Kamargaon meteorite is L6 type ordinary chondrite and (C) Veins of feldspar and troilite exhibiting shock induced melt vein in the Kamargaon meteorite 
2), as well its comparison with the average values for H, L, and LL ordinary chondrites (Hutchison, 2004). Major element concentrations are typical for L-type ordinary chondrites (Table 2). Among these elements, however, the concentrations of $\mathrm{Fe}, \mathrm{Ni}$ and $\mathrm{P}$ are significantly higher than the values in L-type ordinary chondrites. Notably, the concentration of these three elements is similar to that of H-type ordinary chondrites. In total, the abundances of 33 trace elements and rare earth elements (REEs) were determined. Elements analyzed by ICP-MS include (by increasing Z) Sc, V, Cr, Co, Ni, Cu, Zn, Ga, Rb, $\mathrm{Sr}, \mathrm{Y}, \mathrm{Zr}, \mathrm{Nb}, \mathrm{Cs}, \mathrm{Ba}$, all 14 REEs (La, Ce, Pr, Nd, Sm, Eu, Gd, Tb, Dy, Ho, Er, Tm, Yb, Lu), Hf, Ta, Pb, $\mathrm{Th}$, and U. The REE abundance of Kamargaon is shown in Fig. 3. The $\mathrm{Pb}, \mathrm{Cr}, \mathrm{Sr}$ and $\mathrm{Ba}$, abundance in Kamargaon meteorite is higher than that of $\mathrm{H}$ chondrites. Minor deviations from the typical values of abundances of REEs in Kamargaon, namely La, $\mathrm{Ce}$ and $\mathrm{Nd}$, as compared to $\mathrm{L}$ chondrites. The total REE is $6.6 \mathrm{ppm}$ and is enriched in LREE (5.9 ppm). The REE pattern shows LREE enrichment $\left[(\mathrm{La} / \mathrm{Sm})_{\mathrm{cn}}\right.$ 3.6] with flat HREE $\left.\left[(\mathrm{Tb} / \mathrm{Yb})_{\mathrm{cn}} 1.2\right)\right]$ and a prominent negative $\mathrm{Eu}$ anomaly $\left(\mathrm{Eu}^{*} 0.76\right)$ indicating that plagioclase has crystallized and was removed from the melt phase prior to the formation of the rock, and that a reducing environment prevailed during the course of crystallization (Fig. 3).

Table 2: XRF derived major elemental composition of Kamargaon in relation to the composition of ordinary chondrites (H, L and LL groups) and Kaprada

\begin{tabular}{lccccc}
\hline $\begin{array}{l}\text { Element } \\
(w t \%)\end{array}$ & $\mathrm{H}$ & $\mathrm{L}$ & $\mathrm{LL}$ & Kamargaon & Kaprada \\
\hline $\mathrm{Si}$ & 16.9 & 18.5 & 18.9 & 16.8 & 18.12 \\
$\mathrm{Ti}$ & 0.06 & 0.063 & 0.062 & 0.07 & 0.07 \\
$\mathrm{Al}$ & 1.13 & 1.22 & 1.19 & 1.28 & 1.2 \\
$\mathrm{Cr}$ & 0.366 & 0.388 & 0.374 & 0.382 & 0.3 \\
$\mathrm{Fe}$ & 27.5 & 21.5 & 18.5 & 27.2 & 21.5 \\
$\mathrm{Mn}$ & 0.232 & 0.257 & 0.262 & 0.280 & 0.24 \\
$\mathrm{Mg}$ & 14 & 14.9 & 15.3 & 14.1 & 15.3 \\
$\mathrm{Ca}$ & 1.25 & 1.31 & 1.3 & 1.39 & 1.33 \\
$\mathrm{Na}$ & 0.64 & 0.7 & 0.7 & 0.72 & 0.7 \\
$\mathrm{~K}$ & 0.078 & 0.083 & 0.079 & 0.082 & 0.087 \\
$\mathrm{P}$ & 0.108 & 0.095 & 0.085 & 0.15 & 0.14 \\
$\mathrm{Ni}$ & 1.6 & 1.2 & 1.02 & 1.52 & 1.27 \\
$\mathrm{Co}$ & 0.081 & 0.059 & 0.049 & 0.066 & 0.06 \\
$\mathrm{~S}$ & 2 & 2.2 & 2.3 & 1.93 & 2.27 \\
\hline
\end{tabular}

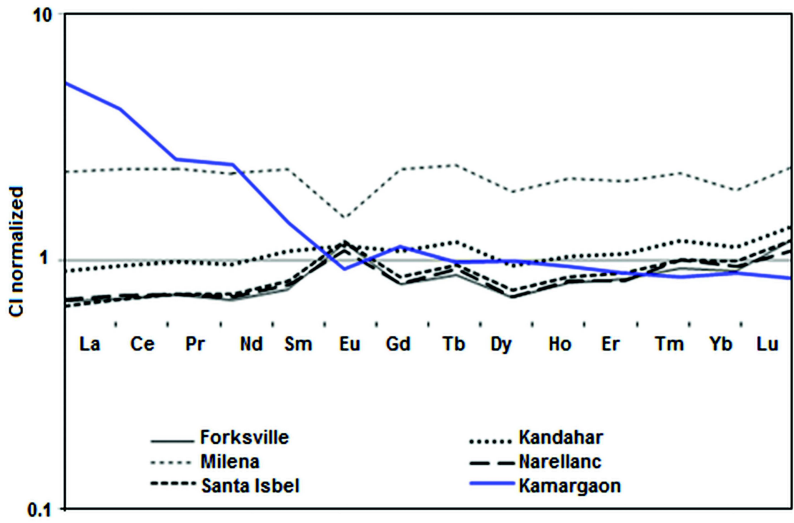

Fig. 3: Cl chondrite normalized REE pattern of Kamargaon with other L6 chondrites (Forksville, Milena, Santa Isbel, Kandahar and Narellanc)

The Fig. 4(A) reveals clear Raman lines attributable to olivine in Kamargaon meteorite. Raman bands in the region $400-800 \mathrm{~cm}^{-1}$ are relatively weak as compared to their infrared counterparts. Raman peaks between $700-1100 \mathrm{~cm}^{-1}$ are attributed to the internal stretching vibrational modes of the $\mathrm{SiO}_{4}$ tetrahedra. In this region, the renowned doublet is found for the $\mathrm{Si}-\mathrm{O}$ symmetric stretching bands at 813 $823 \mathrm{~cm}^{-1}$ and $852-854 \mathrm{~cm}^{-1}$, and a medium wave number anti symmetric $\mathrm{Si}-\mathrm{O}$ stretching band appears at $965-966 \mathrm{~cm}^{-1}$ due to fosterite $\left(\mathrm{F}_{\mathrm{o}}\right)$. The peaks of the $813-852 \mathrm{~cm}^{-1}$ doublet is assigned to a mixed contribution of the symmetric ( $\nu 1)$ and asymmetric (v3) stretching modes of $\mathrm{Si}-\mathrm{O}_{\mathrm{nb}}$ bonds (Non-Bridge Oxygen, NBO) in $\mathrm{SiO}_{4}$ tetrahedra (Lam et al., 1990). Raman spectra indicates the characteristic doublet at $822.06 \mathrm{~cm}^{-1}$ and $851.79 \mathrm{~cm}^{-1}$ from the coupling between the symmetric $(\nu 1)$ and anti symmetric $(\nu 3)$ stretching modes of $\mathrm{Si}-\mathrm{O}_{\mathrm{nb}}$ bonds in $\mathrm{SiO}_{4}$ tetrahedra of olivine (Saikia et al., 2016, 2017b). This peak position may shift upwards as the values of $F_{o}$ increase (Chopelas, 1991). The $F_{o}$ value of an olivine can be determined from the compositional results. The $\mathrm{F}_{\mathrm{o}}$ value of a meteorite corresponds to forsteritic olivines, with about $27.20 \%$ of Fe. The low wave number peak at $572.14 \mathrm{~cm}^{-1}$ occurs due to the bridging oxygen (BO). The medium wave number peak at $916.92 \mathrm{~cm}^{-}$ ${ }^{1}$ indicates polymerization. The $822.06 \mathrm{~cm}^{-1}$ peak has a higher contribution of $\nu 3$ (asymmetric mode) than the $851.79 \mathrm{~cm}^{-1}$ peak. This mode is more easily affected by variations in the $\mathrm{Si}-\mathrm{O}_{\mathrm{nb}}$ force constant, and is also affected by the breakdown of $\mathrm{SiO}_{4}$ during polymerization (Lam et al., 1990). Relative peak height depends on crystal orientation (Ishii, 1978). Therefore, 
systematic variations of high-wave number $\mathrm{Si}-\mathrm{O}$ bands are attributed to decreased distortion of $\mathrm{SiO}_{4}$ tetrahedra. A weak band at 712 and $918 \mathrm{~cm}^{-1}$ corresponds to wadsleyite (Chen et al., 2004). Table 3 represents a comparison of Kamargaon data with theoretical Raman peak positions of different class of ordinary chondrites by Pittarello et al. (2015). Raman peaks (Fig. 4A and B) of Kamargaon at $822.06 \mathrm{~cm}^{-1}$ and $851.79 \mathrm{~cm}^{-1}$ are due to olivine. Peaks at $337.12 \mathrm{~cm}^{-1}, 680.45 \mathrm{~cm}^{-1}$ and $1006.13 \mathrm{~cm}^{-1}$ due to pyroxene is identical to the values for L-chondrites (Pittarello et al. 2015). The full width at half maximum (FWHM) values of the $v 1$ olivine band in the Raman spectra of L6 ordinary chondrites have been related to the degree of crystal structural disorder resulting from shock deformation (Miyamoto \& Ohsumi, 1995), and range from $10 \mathrm{~cm}^{-1}$ to $21 \mathrm{~cm}^{-1}$ for poorly shocked to strongly shocked meteorites respectively. The observed FWHM value of the olivine Raman line at $822.06 \mathrm{~cm}^{-1}(v 1)$ is $\sim 17 \mathrm{~cm}^{-1}$ and is identical to the strongly shock stage. The Raman spectral pattern of end-member chromite (Fig. 4B) consists of a major broad peak near $684 \mathrm{~cm}^{-1}$ and a shoulder near 650 $\mathrm{cm}^{-1}$. Other minor peaks are seen at $639, \sim 615, \sim 518$, $\sim 478$ and $\sim 432 \mathrm{~cm}^{-1}$. The strongest peak at 684 $\mathrm{cm}^{-1}$ is assigned to the $A_{1 \mathrm{~g}}$ mode and this feature presumably is generated by the bonds in $\left(\mathrm{Cr}^{3+}, \mathrm{Fe}^{3+}\right.$, $\left.\mathrm{Al}^{3+}\right) \mathrm{O}_{6}$ octahedra. The trivalent ions lead to a more compact structure and a higher degree of covalency than those in $\mathrm{Fe}^{2+} \mathrm{O}_{4}$ tetrahedra (Wang et al., 2004a). Strong fluorescence at $400-520 \mathrm{~cm}^{-1}$ could hide the intense feldspar Raman bands at around $500 \mathrm{~cm}^{-1}$. On the other hand, FeNi metal has no active modes for Raman spectroscopy and troilite is a weak Raman scatterer (Wang et al., 2004b).
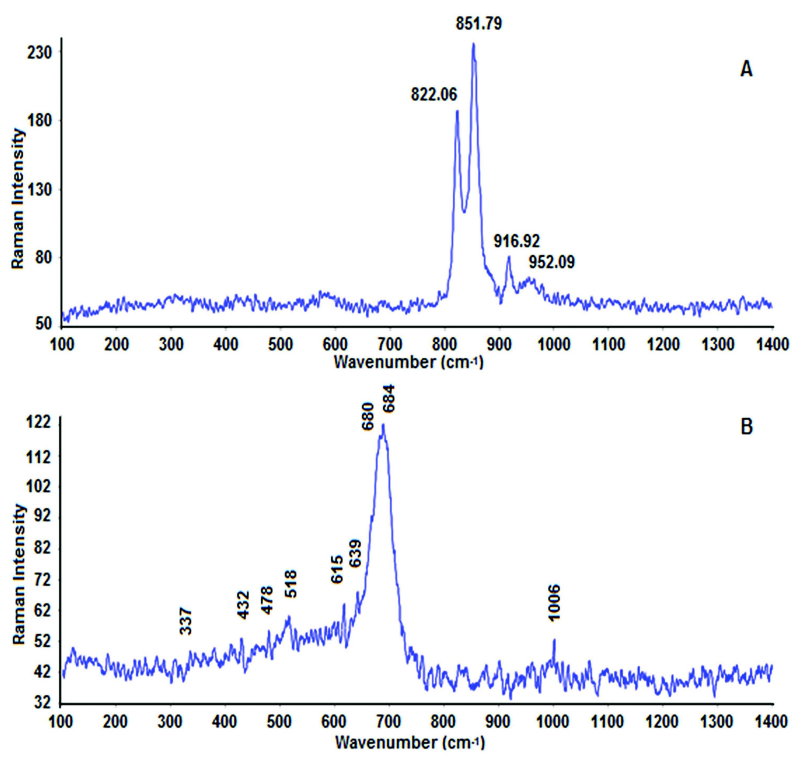

Fig. 4: Raman spectra of the olivine (A) and chromite (B) recorded in the spectral region $100-1400 \mathrm{~cm}^{-1}$ from different points of Kamargaon meteorite

The infrared spectrum of Kamargaon (Fig. 5) reveals numerous absorption bands in $800-1150 \mathrm{~cm}^{-1}$ and $400-700 \mathrm{~cm}^{-1}$ region indicating the presence of silicates in the sample. These band profiles generally depend on the crystalline structure of the silicates and can therefore be used to identify the mineral phases. The absorption features in the decreasing intensities in the $\mathrm{Si}-\mathrm{O}$ stretching region and the $\mathrm{Si}-\mathrm{O}-\mathrm{Si}$ bending vibrations at 1057, 926, 904 and $508 \mathrm{~cm}^{-1}$ is identical to the bands of fayalite $\left(\mathrm{Fe}_{2} \mathrm{SiO}_{4}\right)\left(\mathrm{F}_{\mathrm{a}} 20.80\right)$, the bands found at 995, 884, 839, 616, 548 and $508 \mathrm{~cm}^{-1}$ are identical to the bands of forsterite $\left(\mathrm{Mg}_{2} \mathrm{SiO}_{4}\right)$ and the bands found at 1057, 972, 913, 874 and $533 \mathrm{~cm}^{-1}$ are identical to the bands of enstatite $\left(\mathrm{Mg}_{2} \mathrm{SiO}_{3}\right)$

Table 3: Comparison of Kamargaon Raman peak positions with the chemical group attribution based on theoretical Raman peak position by Pittarello et al. (2015)

\begin{tabular}{lcccc}
\hline \multicolumn{2}{c}{ Chemical group } & Peak $\left(\mathrm{cm}^{-1}\right)$ & Peak B $\left(\mathrm{cm}^{-1}\right)$ & Peak $\left(\mathrm{cm}^{-1}\right)$ \\
\hline $\mathrm{H}$ & $\mathrm{Fa}_{16-20}$ & $821.9-822.3$ & $852.5-853.4$ & - \\
& $\mathrm{Fs}_{14-18}$ & $337.9-339.5$ & $681.2-682.5$ & $1007.8-1009.0$ \\
$\mathrm{~L}$ & $\mathrm{Fa}_{22-26}$ & $821.3-821.7$ & $851.2-852.1$ & - \\
& $\mathrm{Fs}_{19-22}$ & $336.5-337.6$ & $679.9-680.8$ & $1006.6-1007.5$ \\
$\mathrm{LL}$ & $\mathrm{Fa}_{26-32}$ & $820.6-821.3$ & $849.9-851.2$ & - \\
& $\mathrm{Fs}_{22-26}$ & $334.9-336.5$ & $678.6-679.9$ & $1005.5-1006.6$ \\
\multirow{2}{*}{ Kamargaon } & $\mathrm{Fa}_{20.8-25.0}$ & 822.06 & 851.79 & - \\
& $\mathrm{Fs}_{20.4-21.2}$ & 337.12 & 680.45 & 1006.13 \\
\hline
\end{tabular}




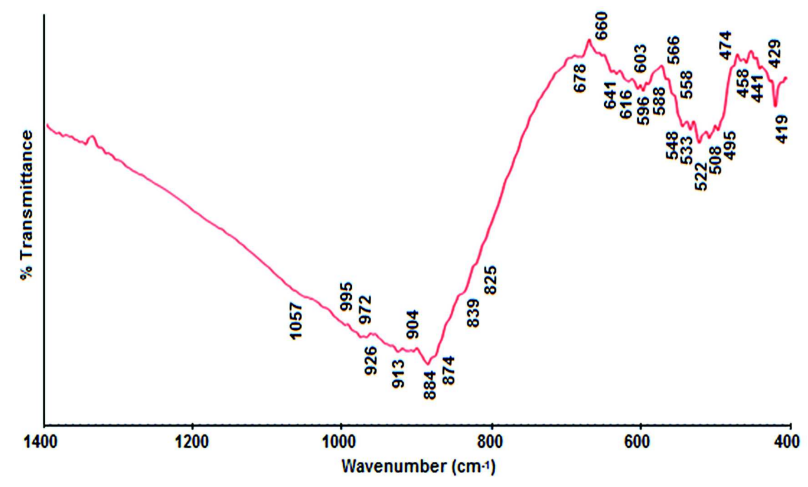

Fig. 5: The infrared spectra of Kamargaon meteorite in the spectral region $1400-400 \mathrm{~cm}^{-1}$, olivine is recorded in $1000-500 \mathrm{~cm}^{-1}$ region

(Gadsden, 1975; Saikia et al. 2011). The observed band at $508 \mathrm{~cm}^{-1}$ can be interpreted as $\mathrm{Si}-\mathrm{O}$ and $\mathrm{Mg}$ $\mathrm{O}$ vibration modes in enstatite $\left(\mathrm{MgSiO}_{3}\right)$ with slight shifts in the matrix (Nakamoto, 1978). The Si-O asymmetric stretching vibration (TO2-T2O5) is observed in between the peaks $995-1057 \mathrm{~cm}^{-1}$. The observed peak positions $913-972 \mathrm{~cm}^{-1}$ and $874-884$ $\mathrm{cm}^{-1}$ are arises due to the $\mathrm{Si}-\mathrm{O}$ asymmetric vibration (TO3) and (T2O7- -TO4) respectively. In the bending vibration region, the peak at $687 \mathrm{~cm}^{-1}$ is arises due to the symmetrical bending vibration of $\mathrm{O}-\mathrm{Si}(\mathrm{Al})-\mathrm{O}$. The $\mathrm{Si}-\mathrm{O}-\mathrm{Si}$ bending vibrations are observed in between $458-495 \mathrm{~cm}^{-1}$.

The powder X-ray diffraction pattern (Fig. 6) shows major phases of pyroxenes (enstatite); olivine (forsterite) and iron (kamacite). The most abundant mineral in Kamargaon meteorite is olivine, followed by pyroxene (enstatite), and iron (kamacite). The peaks (420), (321) and (610) at $28.09^{\circ}, 30.31^{\circ}$, and $31.09^{\circ}$, correspond to Ca-poor orthopyroxene, Ca-poor

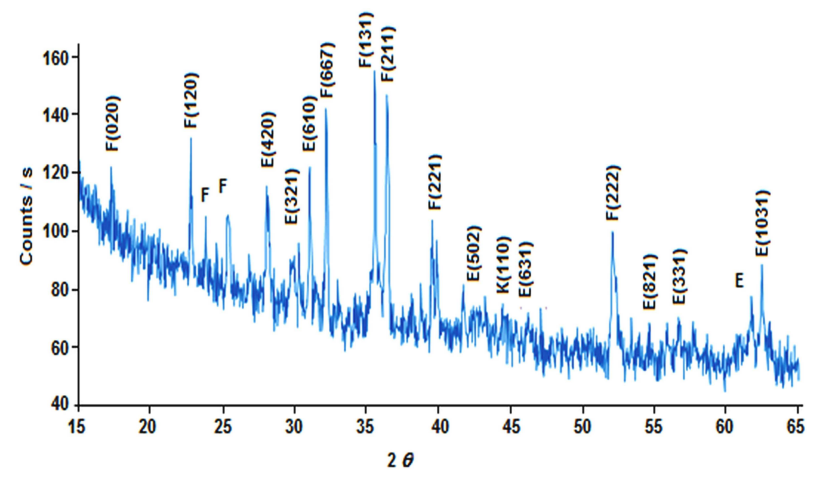

Fig. 6: $\mathrm{X}$ ray diffraction pattern of Kamargaon meteorite (F: forsterite, $\mathrm{E}$ : enstatite, $\mathrm{K}$ : kamacite) clinopyroxene, and Ca-rich pyroxene phases respectively. The orthopyroxene peak (321) at $30.31^{\circ}$ is an indicator of equilibrated chondrite. Generally, the height of peak around $31^{\circ}$ is highest among these three peaks for the equilibrated ordinary chondrite. In this range, the diffraction pattern of Kumargaon exhibits the highest peak at $31.09^{\circ}$ (Fig. 6). Other pyroxene (enstatite) peaks are observed at $41.74^{\circ}$, $46.06^{\circ}, 54.70^{\circ}, 56.62^{\circ}, 61.78^{\circ}$ and $62.44^{\circ}$. The peak (110) appears at $44.47^{\circ}$ is due to kamacite $[\propto-(\mathrm{Fe}$, $\mathrm{Ni})$ ]. The other peaks observed at $17.32^{\circ}, 22.81^{\circ}$, $25.36^{\circ}, 32.23^{\circ}, 35.59^{\circ}, 36.46^{\circ}, 39.61^{\circ}$ and $52.12^{\circ}$ are reveals the presence of olivine (forsterite). The Xray diffraction pattern also confirms of fayalite rich olivine.

\section{Conclusion}

This study represents spectroscopic, compositional and mineralogical investigations of Kamargaon meteorite. The electron-probe microanalysis indicates that the Kamargaon meteorite is an L6 chondrite. The Raman analysis is consistent with the electron-probe microanalysis results. Raman spectral pattern reveals chromite as an end-member. FeNi metal has no active modes for Raman spectroscopy and troilite is a weak Raman scatterer. Following an alternative classification using Raman spectroscopy by Pittarello et al. (2015), the Raman peak positions due to olivine and pyroxene of Kamargaon are identical to the Lchondrites. Observed FWHM value of the olivine Raman line at $822.06 \mathrm{~cm}^{-1}(v 1)$ is $\sim 17 \mathrm{~cm}^{-1}$, which is identical to the strongly shocked stage. Compositional and trace elements abundances show good agreements with L. chondrite. A prominent negative Eu anomaly indicates partial melting or fractional crystallization of the source. X-ray diffraction pattern indicates that the most abundant mineral in Kamargaon meteorite is olivine $(\mathrm{d}=2.4567 \AA)$, followed by pyroxene $(\mathrm{d}=2.8700 \AA)$, and kamacite $(\mathrm{d}=2.0280$ $\AA$ ). The diffraction peak of orthopyroxene at $30.31^{\circ}$ indicates it to be an equilibrated chondrite. Phases of olivine (forsterite) and pyroxenes (enstatite) are also characterized by infrared spectroscopy. The overall spectroscopic analysis of Kamargaon is consistent with the geochemical compositional analysis. While this manuscript was under review, a report on the fall of the Kamargaon meteorite has been reported by Ray et al. (2017). Our present study confirms the classification of the meteorite as L6 chondrite. 


\section{Acknowledgements}

This paper is dedicated to $80^{\text {th }}$ Birthday of Professor E S Raja Gopal, Department of Physics, Indian Institute of Science, Bangalore. We thank, Directors, National Geophysical Research Institute (NGRI), Hyderabad and Indian Institute of Technology, Guwahati (IITG) for analytical facilities; Professor Laurence Garvie

\section{References}

Armstrong J T (1991) Quantitative elemental analysis of individual microparticles with electron beam instruments. In Heinrich K. F. J. and Newbury D. E. (Ed.) Electron probe quantitation, Plenum Press, New York, 261-315 pp

Bhandari N, Murty S V S, Shukla P N, Mahajan R R, Shukla AD, Suthar K M, Parthasarathy G and Paliwal B S (2005) Bhawad LL6 chondrite: chemistry, petrology, noble gases, nuclear tracks and cosmogenic radionuclides in Meteorit Planet Sci 40 1015-1022

Bhandari N, Murty S V S, Shukla PN, Mahajan R R, Shukla AD, Lashkari G, Sisodia M S, Tripati RR, Parthasarathy G, Verma H C and Franchi I A (2008) Aarki (L5) chondrite: first meteorite find in Thar desert of India in Meteorit Planet Sci 43 761-770

Bhandari N, Murty S V S, Mahajan R R, Parthasarathy G, Shukla P N, Sisodia M S and Rai V K (2009) Kaprada (L5/6) chondrite: chemistry, petrography, noble gases, and nuclear tracks in Planet Space Sci 57 2048-2052

Brearley A J and Jones R H (1998) Reviews in mineralogy and geochemistry in Rev Min 36398

Chen M, Ahmed El Goresy A E and Gillet P (2004) Ringwoodite lamellae in olivine: Clues to olivine-ringwoodite phase transition mechanisms in shocked meteorites and subducting slabs in PNAS 101 15033-15037

Chopelas A (1991) Single crystal Raman spectra of forsterite, fayalite, and monticellite in Am Mineral 76 1101-1109

Gadsden J A (1975) Infrared spectra of Mineral and related Inorganic Compounds. Butterworths, USA, 160-175pp

Grady M M (2000) Catalogue of meteorites. Cambridge University Press, Cambridge, UK

Ghosh S, Murty S V S, Shukla P N, Shukla A D, Mahajan R R, Bhandari N. Pant N C, Ghosh J B and Shome S (2002) Fall, classification and cosmogenic records of the Sabrum(LL6) chondrite in Meteorit Planet Sci 37 439-448

Hutchison R (2004) Meteorites: a Petrologic, Chemical, and Isotopic Synthesis. Cambridge University Press, for useful discussion. We are grateful to the Editor Dr. A K Singhvi and the anonymous reviewers for their constructive comments. We thank PLANEX program, PRL, and Space Application Centre, Department of Space, Government of India, for their valuable support. We also thank to Dr. S Sarmah, IIT Guwahati, and Dr. J R Chetia, Dibrugarh University for their assistance with the spectroscopic analysis.

Cambridge, UK, 506 pp

Iishi K (1978) Lattice dynamics of forsterite in Am Mineral 63 1198-1208

Lam P K, Yu R, Lee M W and Sharma S K (1990) Relationship between crystal structure and vibrational mode in $\mathrm{Mg}_{2} \mathrm{SiO}_{4}$ in Am Mineral 75 109-119

Miyamoto M and Ohsumi K (1995) Micro Raman spectroscopy of olivines in L6 chondrites: Evaluation of the degree of shock in Geophys Res Lett 22 437-440

Nakamoto K (1978) Infrared and Raman Spectra of Inorganic and Coordination Compounds, John Wiley and Sons, New York, 105-139 pp.

Philip A B, Alex W R B and Tim Jull A J (2000) Ancient Meteorite Finds and the Earth's Surface Environment in Quat Res 53 131-142

Pittarello L, Baert K, Debaille V and Claeys P (2015) Screening and classification of ordinary chondrites by Raman spectroscopy in Meteorit Planet Sci 50 1718-1732

Ray D, Mahajan R R, Shukla A D, Goswami T and Chakraborty S (2017) Petrography, classification, oxygen isotopes, noble gases, and cosmogenic records of Kamargaon (L6) meteorite: The latest fall in India in Meteorit Planet Sci 52 1744-1753

Reisener R J and Goldstein J I (2003) Ordinary chondrite metallography, Part 2. Formation of zoned and unzoned metal particles in relatively unshocked $\mathrm{H}, \mathrm{L}$ and $\mathrm{LL}$ chondrites in Meteorit Planet Sci 38 1679-1696

Rubin A E (1990) Kamacite and olivine in ordinary chondrites: Intergroup and intragroup relationships in Geochim Cosmochim Acta 54 1217-1232

Rubin A E (2005) Relationships among intrinsic properties of ordinary chondrites: Oxidation state, bulk chemistry, oxygen-isotopic composition, petrologic type and chondrule size in Geochim Cosmochim Acta 69 4907-4918

Saikia B J, Parthasarathy G, Sarmah N C and Baruah G D (2007) Organic compounds in H5 meteorite: Spectroscopic investigation of Dergaon H5 chondrite in Geochim 
Cosmochim Acta 71 A867

Saikia B J and Parthasarathy G (2008) Spectroscopy of Dergaon meteorite in Geochim Cosmochim Acta 72818

Saikia B J, Parthasarathy G and Sarmah N C (2009a) Fourier transform infrared spectroscopic characterization of Dergaon H5 chondrite: Evidence of aliphatic organic compound in Nat Sci 7 45-51

Saikia B J, Parthasarathy G and Sarmah N C (2009b) Spectroscopic characterization of olivine $\left[(\mathrm{Fe}, \mathrm{Mg})_{2} \mathrm{SiO}_{4}\right]$ in Mahadevpur $\mathrm{H} 4 / 5$ ordinary chondrite in $J$ Am Sci 5 71-78

Saikia B J, Parthasarathy G and Borah R R (2011) Spectroscopic characterization of olivine due to $\mathrm{Fe} / \mathrm{Mg}$ in Dergaon chondrite in Mineral Mag $\mathbf{7 5} 1780$

Saikia B J, Parthasarathy G, Borah R R and Borthakur R (2016) Raman spectroscopic study of Dergaon H5 and Mahadevpur H4/5 chondrite in 47th Lunar and Planetary Science Conference.\#1799

Saikia B J, Parthasarathy G and Borah R R (2017a) Raman spectroscopy of Kamargaon L6 ordinary chondrite in 48th Lunar and Planetary Science Conference.\#1979
Saikia B J, Parthasarathy G and Borah R R (2017b) Nanodiamonds and silicate minerals in ordinary chondrites as determined by micro-Raman spectroscopy in Meteorit Planet Sci 52 1146-1154

Smith B A and Goldstein J I (1977) The metallic microstructures and thermal histories of severely reheated chondrites in Geochim Cosmochim Acta 41 1061-1072

Stoffler D, Keil K and Scott E R D (1991) Shock metamorphism of ordinary chondrites in Geochim Cosmochim Acta $\mathbf{5 5}$ 3845-3867

vanSchmus W R and Wood J A (1967) A chemical-petrologic classification for the chondritic meteorites in Geochim Cosmochim Acta 31 747-765

Wang A, Kuebler K E, Jolliff B L and Haskin LA (2004a) Raman spectroscopy of Fe-Ti-Cr-oxides, case study: Martain meteorite EETA79001 in Am Mineral 89 665-680

Wang A, Kuebler K, Jolliff B and Haskin LA (2004b) Mineralogy of a Martian meteorite as determined by Raman spectroscopy in J Raman Spectros 35 504-514. 